Yves Libert

Isabelle Merckaert

Christine Reynaert

Nicole Delvaux

Serge Marchal

Anne-Marie Etienne

Jacques Boniver

Jean Klastersky

Pierre Scalliet

Jean-Louis Slachmuylder

Darius Razavi

Received: 8 March 2005

Accepted: 7 July 2005

Published online: 29 July 2005

(C) Springer-Verlag 2005

This research program was supported by the "Fonds National de la Recherche Scientifique-Section Télévie" of Belgium, the

"Fonds d'Encouragement à la Recherche de l'Université Libre de Bruxelles" (Brussels, Belgium) and the CAM Training and

Research Group (Brussels, Belgium).

Y. Libert · I. Merckaert · N. Delvaux ·

J. Klastersky · D. Razavi $(\bowtie)$

Université Libre de Bruxelles,

Av. F. Roosevelt, 50, CP 191,

1050 Brussels, Belgium

e-mail: drazavi@ulb.ac.be

Tel.: +32-2-6504581

Fax: +32-2-6502209

Y. Libert · C. Reynaert · P. Scalliet

Université Catholique de Louvain,

Louvain-la-Neuve and Brussels,

Belgium

Y. Libert · S. Marchal •

J.-L. Slachmuylder

CAM Training and Research Group,

Brussels, Belgium

A.-M. Etienne · J. Boniver

Université de Liège,

Liège, Belgium

\title{
Does psychological characteristic influence physicians' communication styles? Impact of physicians' locus of control on interviews with a cancer patient and a relative
}

\begin{abstract}
Context: Physicians' psychological characteristics may influence their communication styles and may thus interfere with patientcentred communication. Objective: Our aim was to test the hypothesis that, in interviews with a cancer patient and a relative, physicians with an "external" locus of control (LOC; who believe that life outcomes are controlled by external forces such as luck, fate or others) have a communication style different from that of physicians with an "internal" LOC (who believe that life outcomes are controlled by their own characteristics or actions). Design, setting, participants and intervention: Eighty-one voluntary physicians practising in the field of oncology were recorded while performing an actual and a simulated interview with a cancer patient and a relative. Main outcome measures: Physicians'

on this scale were compared using Student's $t$ test. Results: In actual interviews, physicians with an "external" LOC talked more to the relative $(P=0.017)$ and used more utterances with an assessment function $(P=0.010)$ than physicians with an "internal" LOC. In simulated interviews, physicians with an "external" LOC used less utterances that give premature information $(P=0.031)$ and used more utterances with a supportive function, such as empathy and reassurance $(P=0.029)$, than physicians with an "internal" LOC. Conclusion: These results provide evidence that physicians' LOC can influence their communication styles. Physicians' awareness of this influence constitutes a step towards a tailoring of their communication skills to every patient's and relative's concerns and needs and thus towards a patient-centred communication.
\end{abstract} communication skills were assessed using the Cancer Research Campaign Workshop Evaluation Manual. Physicians' LOC was assessed using the Rotter I-E scale. The communication skills of the upper and lower quartiles of physicians in respect of their scores
Keywords Physicians' locus of control - Communication skills . Patient-centred communication . Interviews with a cancer patient and a relative

\section{Introduction}

Today, "patient-centred" communication is more favoured and is increasingly being regarded as crucial for the delivery of high-quality care by doctors [1]. Communication skills have thus become an important component of physi- cians' professional competence [2]. Communication skills are, indeed, the necessary tools required to assess [3], inform [4] and support [5] patients adequately. Physicians' adequate information and support should take more into account patients' physical symptoms, distress and concerns, as well as the interview's coherence. As numerous 
patients are reluctant to spontaneously disclose their concerns and distress $[6,7]$, assessment skills promoting disclosure are crucial for physicians. They are also useful for physicians in order to assess patients' wish to be informed [8] and their processing [9] and memorization [10] of the information given to them. Assessment skills promoting disclosure are thus the key to appropriate information and support. Unfortunately, the use of such communication skills is particularly difficult when the task is breaking bad news in a highly emotional context, as it is often the case in oncology.

Theoretical models have previously suggested that psychological characteristics of physicians, such as knowledge and attitudes, outcome expectancies, self-efficacy or perceived professional support, could be important determinants of physicians' use of communication skills in interviews with cancer patients [11]. Researches on physicians' professional competence should thus study whether specific characteristics of physicians could influence their communication styles in interviews with cancer patients. Parle et al. [11] underlined in their theoretical model that, among these determinants, psychological characteristics of physicians associated with their perceived personal control over outcome expectancies could play a key role. More precisely, they hypothesized that only health care professionals who have enough confidence in maintaining the control of the interview would be willing to use communication skills promoting patients' disclosure of concerns and distress and, consequently, would have the opportunity to provide them with more appropriate information and support. Psychological characteristics of physicians associated with their perceived personal control over outcome expectancies may thus, in theory, influence their communication skills in interviews with cancer patients and lead to different communication styles.

It has been demonstrated that individuals could greatly differ with regard to their perceived control over outcome expectancies and that this perceived personal control could influence their behaviour. This difference has been approached through one of the most studied psychological concepts: the locus of control (LOC). The LOC, introduced by Rotter [12] in 1966, refers to a generalized belief regarding the extent to which life outcomes are controlled by external forces such as luck, fate or others ("external" control) or by one's own characteristics or actions ("internal" control). In Rotter's social learning theory, the LOC is defined as a psychological characteristic that determines a person's position on a continuum between the belief that life outcomes are exclusively controlled by external forces and the opposite belief that life outcomes are exclusively controlled by an individual's own characteristics or actions. Although LOC measurements can be sensitive to strong environmental changes (e.g. a divorce) [13], longitudinal studies have shown that, typically, an adult individual's LOC tends to remain stable [14]. As physicians' confidence in maintaining the control in interviews could in- fluence their use of communication skills, a previous study has tested whether physicians' position on this continuum could lead to different communication styles in interviews with cancer patients [15]. The results of this study highlight that, for the same level of utterances with an assessment function, physicians with an "external" LOC use more utterances that give appropriate information than physicians with an "internal" LOC. They thus give more information after exploring patients' feelings; the information given is more realistic and takes more into account the interview's coherence. These results could be explained by the concept of LOC itself. Physicians with an "external" LOC believe that life outcomes are more controlled by external forces, such as others, than by one's own characteristics or actions. When they give information, they could therefore be more focused on external cues, such as concerns and requests for information, expressed by their interlocutors. In contrast, physicians with an "internal" LOC believe that life outcomes are more controlled by one's own characteristics or actions than by external forces. When they give information, they could therefore be more focused on internal cues, such as their own representations of their interlocutors' concerns and their need for information.

In the previous study, the communication skills of physicians were analysed in the context of interviews wherein cancer patients were not accompanied by a relative. In cancer care, however, relatives often accompany patients for their medical interviews [16]. Accompanying relatives are predominantly spouses, followed indeterminately by children, parents or siblings [17]. They are thus also often patients' primary caregivers [17]. As patients' caregivers, they could be reliable witnesses of patients' difficulties in coping with cancer [18-21]. Therefore, asking them to express their perceptions of patients' physical symptoms, distress and concerns could help physicians in informing and supporting their patients more appropriately. Moreover, the increase in outpatient care and the shortening of hospital length of stay associated with an increase in cancer patients' life expectancy have led many relatives of cancer patients to face an increasing amount of emotional as well as practical tasks [22]. Those tasks are often complex and highly burdensome and can result in heightened distress levels among relatives. Research results indeed suggest that family members of cancer patients show signs of depression and anxiety, restrict roles and activities, experience strain in marital relationships and show diminished physical health [23]. Between 10 and $30 \%$ of relatives are probable cases of psychiatric morbidity - a level that is likely to increase as the illness advances and the treatment becomes palliative [22]. Finally, it is important to note that caregivers' bad adjustment has been associated with patients' poor social rehabilitation [24], poor treatment adherence [25] and increased emotional distress $[26,27]$. Physicians' communication skills addressed to the relatives (who could improve this adjustment) could thus improve patient support and quality of life. It is there- 
fore important to specifically study three-person interviews. Unfortunately, however, this has rarely been done. The few existing studies have shown that, when a relative was present, the interview was slightly longer, physicians were likely to provide more information [17] and older patients were likely to be less expressive and assertive [28]. In physicians' communication skills training, a recent study showed that post-training improvements concerning physicians' communication towards patients and relatives were different. Six consolidation workshops, which were $3 \mathrm{~h}$ in length and conducted after a 2.5-day basic training program, improved communication skills addressed to patients and relatives even if the transfer of skills addressing relatives' concerns remained limited [29].

Researches on physicians' professional competence should thus study whether psychological characteristics of physicians could influence their communication styles in interviews with a cancer patient and a relative. The aim of this study is to test whether physicians' LOC is a determinant of these styles. Our hypothesis proposes that, compared to physicians with an "internal" LOC, who believe that life outcomes are controlled by their own characteristics or actions, physicians with an "external" LOC-because they believe that life outcomes are controlled by external forces such as luck, fate or otherswould take more into account patients' and relatives' concerns or requests for information and would consequently talk more to relatives and use more utterances with an assessment function (such as assessing, checking or summarizing), more utterances that give appropriate information and more utterances with a supportive function (such as reassuring, being empathic, making educated guesses, confronting reality or alerting to reality).

\section{Subjects and methods}

\section{Recruitment}

Data came from the baseline assessment of a randomized controlled communication skills training program designed for medical specialists and developed in Belgium from 1999 to 2001. All French-speaking Belgian physicians dealing with cancer patients were invited by mail to take part in the training program $(n=3,706)$, and all institutions devoted to cancer care were contacted and asked to deliver an internal mail $(n=2,741)$.

To be included in the study, physicians had to be specialized in medical or surgical oncology, radiotherapy, haematology, gynaecology and so forth. They had to be working with cancer patients (part time or full time), to show an interest for a psychological training focusing on physician-patient-relative communication and to be willing to participate in the training program and its assessment procedure. They also had to speak French. Physicians refusing the assessment procedure and those already par- ticipating in another psychological training program during the assessment period were excluded from the study.

\section{Assessment procedure}

The assessment procedure included two actual and two simulated interviews (one with and one without a patient's relative), as well as a set of questionnaires. Only results concerning actual and simulated interviews with a patient and a relative will be reported here. The local ethics committee approved of the study.

\section{Actual interview}

One actual interview with a patient and a relative was taperecorded. Patients and their relatives were chosen by physicians according to the following inclusion criteria: breaking of a news, whether bad, neutral or good; and the patient and the relative are more than 18 years old, are able to speak and read French, are free from any cognitive dysfunction and have given their written informed consent. Data were provided by physicians following the interview regarding patients' diagnosis (type of cancer, months since diagnosis and disease status), prognosis and current cancer treatment and the type of information (diagnosis-related or not) and news given (bad, good or neutral).

\section{Simulated interview}

The simulated interview was audiotaped and videotaped. It concerned breaking a breast cancer diagnosis. The actors were trained to carefully maintain the same behaviours and the same high emotional level throughout the study. Simulated interviews were chosen to increase the emotional level of the interview, to standardize patients' history and reactions and to standardize the interview's characteristics. This was carried out because simulated interviews have become increasingly accepted over their 30 -year history as a valid method used to represent how a physician would perform with real patients [30-37]. Simulated interviews, moreover, allow to reduce the possible bias that may derive from a wide range of patients' history and reactions and from a wide range of interview characteristics.

In the simulated interview, the actors were instructed to express concerns about the medical and familial consequences of the disease. The simulated husband was encouraged to actively seek information and to relate marital problems, such as a lack of communication between the couple and the simulated wife's excessive wish for autonomy.

Before the simulated interview, the physician had enough time to fill in the questionnaires and to read the clinical description and goals of the interview. In the re- 
cording room, the physician was then introduced to the actors and told that, after $20 \mathrm{~min}$, the interview would end. A clock was available for time management, and the recording room was made to look as realistic as possible.

Interview rating system

Audiotapes of both actual and simulated interviews were transcribed. All transcripts were assessed for their quality and then rated by trained psychologists. Ratings were based on the French translation and adaptation of the Cancer Research Campaign Workshop Evaluation Manual (CRCWEM) [38]. The CRCWEM was used to assess the form, function and emotional level of each utterance. A new coding system was created to identify whether the utterance was directed to the patient exclusively or not. A new utterance was coded for physicians whenever there was a change of form or function, and for patients and relatives whenever there was a change in the emotional depth of the utterance. Only results concerning the direction and function of each physician's utterance will be reported here. Only the first $20 \mathrm{~min}$ of both types of interviews was rated.

The function of those utterances could aim to introduce or close the interview; to assess (elicit, clarify, check or summarize psychosocial or general) concerns; to acknowledge patients' or relatives' utterances (showing that one has heard the patient's or the relative's words by saying "Yes", "I see", "Uh, huh" and so forth); to give appropriate information; to reassure or express empathy (showing an understanding of the patient's or the relative's feelings by making a brief statement such as "How upsetting for you"); to interpret the patient's or relative's thoughts or beliefs by making educated guesses (making a sensible and warranted guess at the patient's or relative's thoughts, feelings and so forth), confronting the patient's or the relative's thoughts and beliefs or alerting to the reality of the situation; and, finally, to negotiate which steps have to be taken next (making statements that show respect for the patient's or the relative's view and giving them an opportunity to disagree). Providing information and reassurance before exploring the patient's or the relative's feelings, of an unrealistic kind, or without taking interview coherence into account is considered premature. Interviews with a patient and a relative intend to state clearly to whom each utterance is directed. For each utterance, a new coding was thus created to identify whether the physician talked to the relative or not.

Interviews were rated by 14 trained psychologists, who were intensively trained. The training included getting acquainted with the rating system by reading the manual, doing rating exercises and being supervised by the rater coordinator. Every rater had to qualify by passing a validating test. Raters who did not succeed in the validating test were further trained and invited to take part in another validating test. Before beginning to rate any study tape, every rater had to reach at least the following concordance rate with the validating test: $85 \%$ for the rating of the form of utterances, $67 \%$ for the functions, $60 \%$ for the content categories and $71 \%$ for the emotional level of the exchanges. Moreover, in order to ensure quality control and avoid rating conflicts, all raters were systematically supervised by the rater coordinator to check the accuracy of their ratings. Finally, ratings were checked throughout the process for inconsistencies.

\section{Questionnaires}

Before the interviews, physicians, patients and relatives were asked to complete a set of questionnaires. Before the actual interview, patients and relatives completed a sociodemographic questionnaire, the Hospital Anxiety and Depression Scale (HADS) and the Multidimensional Health Locus of Control (MHLC) scale. Moreover, the evaluator assessed the patient's and the relative's functional impairment using the Karnofsky Performance Status (KPS). Before the simulated interview, physicians completed a socio-professional questionnaire, the Rotter I-E scale, the Semantic Differential Attitude Questionnaire (SDAQ), the Maslach Burnout Inventory (MBI) and the Job Stress Survey (JSS).

Physicians'socio-professional data Data were collected on physicians' age, gender, medical speciality, whether or not medical specialization was achieved, number of years of practice in medicine and oncology, number of cancer patients cared for last week, type of medical practice and whether or not they had some previous communication skills training workshops in the last year.

Rotter I-E scale A validated French translation of the Rotter I-E scale [12] by Salehi [39] was used in this study to measure physicians' LOC. This scale is a 29 -item selfreport scale with a scoring range from 0 ("internal" LOC) to 23 ("external" LOC), excluding six buffer items. It is designed to measure the respondents' perceived ability to influence events in their own life. Individuals with an "external" LOC believe that external forces such as luck, fate or other individuals control their lives. In contrast, individuals with an "internal" LOC believe that fate and fortune are within their own personal control. To our knowledge, no previous study has assessed the general LOC of medical specialists dealing with cancer patients. Among the few studies in which physicians' LOC has been assessed, only the study of May and Revicki [40] used the Rotter I-E scale. In their sample of 210 family physicians, they found a mean score of $7.1(\mathrm{SD}=4.5)$. 
$S D A Q$ The French translation [41] of the SDAQ [42] was used to assess physicians' attitudes on psychosocial aspects of cancer. This questionnaire includes a list of 20 attitudes. The contrasting adjectives remain the same for each concept scored. Each attitude is scored on 13 semantic differential scales ranging from 1 to 7 , from the positive to the negative pole. A score of 4 (neutral) is allotted whenever an answer is missing. Attitudes are measured by adding up scores obtained for each item on the 13 scales and then dividing the result by 13 . The 20 attitudes are grouped into five factors and a total score is computed. Factors reflect attitudes about oneself (four items), attitudes towards cancer and death (three items), personal growth (three items), professional relationships (four items) and occupational attitudes (six items). For each of the five factors, an average index is obtained by averaging the scores of the factors' constituent attitudes. The total score is obtained by averaging the scores of all attitudes.

MBI The French-translated version [43] of the MBI [44] was used to assess the physicians' level of burnout. This self-report inventory is a 22 -item seven-point Likert scale ranging from never (0) to daily (6). It assesses three dimensions of the burnout syndrome: emotional exhaustion (feelings of being emotionally overextended and exhausted by work; nine items), depersonalization (an unfeeling and impersonal response towards patients; five items) and personal accomplishment (feelings of competence and successful achievement in work with patients; eight items). In a sample of nurses and physicians $(n=123)$, a score of 18 or less for emotional exhaustion, 5 or less for depersonalization and 40 or more for personal accomplishment defines a low level of burnout. In contrast, a score of 27 or more for emotional exhaustion, 10 or more for depersonalization and 33 or less for personal accomplishment defines a high level of burnout. Middle level is defined by the values included between those scores [43].

JSS We used the French translation of the JSS [45], a 30item psychometric instrument designed to assess the perceived severity (intensity) and frequency of occurrence of working conditions that are likely to affect adversely the psychological well-being of employees who are exposed to them. Subjects first rate, on a nine-point scale, the relative amount (severity) of stress that they perceive to be associated with each of the 30 JSS job stressors as compared to a standard stressor event, "Assignment of disagreeable duties", which is assigned a value of " 5 ". Respondents are asked to report, on a scale from 0 to $9+$ days, the number of days on which each workplace stressor was experienced during the preceding 6 months. Summing the ratings of each of the 30 individual JSS items provides overall severity and frequency scores, as well as an overall job stress index score, based on the sum of the cross products of the severity and frequency scores. To our knowledge, no previous study has assessed the professional stress of physicians using JSS. In a sample of 1,781 working adults employed in university and corporate work settings, the stress severity mean ranged from $148.06(\mathrm{SD}=37.63)$ to $146.69(\mathrm{SD}=32.41)$, the stress frequency mean ranged from 107.25 $(\mathrm{SD}=52.20)$ to 109.39 $(\mathrm{SD}=50.82)$ and the stress index mean ranged from 61.31 $(\mathrm{SD}=34.93)$ to $60.81(\mathrm{SD}=32.32)[46]$.

Patients' and relatives' socio-demographic data Each patient and each relative provided socio-demographic information, including age, gender and school level completed.

HADS The HADS [47] is a four-point 14-item self-report instrument assessing anxiety and depression in physically ill subjects. This scale was translated into French and validated in a sample of cancer in-patients [48]. The use of the total score is recommended to assess psychological distress. Scores of $0-12$ indicate no disorder, 13-18 indicate adjustment disorders and $>18$ indicate major depressive disorders [48].

MHLC The MHLC scale [49] contains 18 items of selfreport statements concerning beliefs about what controls health. Each statement is rated on a six-point scale as to the degree of agreement. Three measures are given: Internality of Health Locus of Control (IHLC; the degree to which an individual believes that one is responsible for one' own health or illness), Chance Externality of Health Locus of Control (CHLC; the degree to which an individual believes that luck, chance, fate or uncontrollable factors are responsible for health or illness) and Powerful Others' Externality of Health Locus of Control (PHLC; the degree to which an individual believes that one's own health or illness is determined by important figures such as physicians and other health professionals or parents). Each HLC subscale is scored from 6 (low) to 36 (high). It is generally assumed that the chance externality and powerful others' externality of HLC beliefs merely provide a mirror reflection of the internality dimension [50].

KPS The KPS [51] is a commonly used measure of cancer patients' functional impairment that has adequate interrater reliability, concurrent validity and discriminant validity [52]. A patient scoring under 80 on this scale is not able to achieve daily life activities.

\section{Statistical analysis}

Physicians unable to accrue a patient and a relative for the actual interview scheduled in the assessment procedure but who participated in the simulated interview could be considered evaluable. Data were analysed using SPSS10.0 (1999; Chicago, IL, USA). Due to the normal distribution of the physicians' LOC in our sample (KolmogorovSmirnov test $=0.089 ; P=0.171$ ), parametric statistical ana- 
lyses were performed. Descriptive analyses were first performed on the total sample. Physicians', patients' and relatives' continuous variables of the upper $(22 \%)$ and lower $(27 \%)$ quartiles of physicians in respect of their Rotter I-E scale scores were compared using Student's $t$ test (the cut-off point could not be strictly established on the top and bottom $25 \%$ of the Rotter I-E scale distribution because of ex aequo scores). For physicians', patients', relatives' and actual interviews' discrete variables, chi-square tests were performed. Finally, to test our hypothesis, physicians' communication skills in the upper and lower quartiles of physicians in respect of their Rotter I-E scale scores were compared using the Student's $t$ test.

\section{Results}

Physicians' socio-professional characteristics

Owing to the low response rate to the recruitment procedure (only 90 potentially interested subjects responded to the mail), 214 medical specialists dealing with cancer patients, including the 90 potentially interested, were actively contacted by phone. A total of 163 of them were met individually, and 21 information sessions were also organized in institutions devoted to cancer care. A total of 173 physicians were met during those sessions. Following this process, 113 physicians registered for the training, $76 \mathrm{com}$ pleted the actual interview and 81 physicians completed the simulated interview. A comparison of physicians who completed the actual interview and physicians who did not showed no statistically significant differences for age, gender and number of years of practice. The reasons for the very small number of physicians willing to enter the training program were often the training and the assessment procedure durations that were not compatible with their workload.

Among the 81 medical specialists who completed the simulated interview, 45 were male and 36 were female. Their mean age was 42 years old ( $\mathrm{SD}=7.3$ years). Our sample included 22 oncologists $(27.2 \%)$, 9 radiotherapists (11.1\%), 10 haematologists $(12.4 \%), 18$ gynaecologists $(22.2 \%)$ and 22 other specialities $(27.2 \%)$ (seven lung specialists [8.6\%], three gastroenterologists $[3.7 \%]$, one palliative care specialist [1.2\%], two ear-nose-throat specialists $[2.5 \%]$, two geriatricians [2.5\%], two general surgeons $[2.5 \%]$, one plastic surgeon $[1.2 \%]$, one dermatologist $[1.2 \%]$, one medical biology specialist [1.2\%] and two urologists $[2.5 \%])$. Only six of them have not achieved their medical specialization training (7.4\%). Physicians had a mean of 16 years $(\mathrm{SD}=7.2$ years) of medical practice and 14 years $(\mathrm{SD}=7.5)$ of practice in the field of oncology. On average, they had cared for 25 cancer patients $(S D=22.5)$ in the last week. In all, 69 of them performed hospital practice $(85.2 \%), 39$ practiced in a 1 -day clinic $(48.2 \%)$ and 29 performed private practice $(35.8 \%)$. Finally, two physi- cians $(2.5 \%)$ had some communication skills training workshops in the last year.

Physicians' mean score on the Rotter I-E scale was 9.23 $(\mathrm{SD}=3.46)$. Our physicians' sample is thus more "external" than the family physicians' sample used by May and Revicki [40]. In our statistical analysis, the upper and lower quartiles of the Rotter I-E scale distribution were chosen to define interviews led by physicians with an "internal" LOC $(n=22$; Rotter I-E score $=0-7)$ or physicians with an "external" LOC ( $n=18$; Rotter I-E score $>11)$. Concerning their socio-professional characteristics, the only two statistically significant differences found between both groups indicated that all haematologists were in the group of physicians with an "external" LOC and that the two

Table 1 Socio-professional characteristics of physicians with an "internal" LOC and physicians with an "external" LOC (upper and lower quartiles of the Rotter I-E scale scores distribution)

\begin{tabular}{|c|c|c|}
\hline Characteristics & Internal LOC & External LOC \\
\hline \multicolumn{3}{|l|}{ Age (years) } \\
\hline Mean (SD) & $42.6(6.3)$ & $39.2(5.7)$ \\
\hline \multicolumn{3}{|l|}{ Gender } \\
\hline Male & $16(72.7)$ & $8(44.4)$ \\
\hline Female & $6(27.3)$ & $10(55.6)$ \\
\hline \multicolumn{3}{|c|}{ Medical speciality } \\
\hline Oncology & $5(22.7)$ & 7 (38.9) \\
\hline Radiotherapy & $3(13.6)$ & $2(11.1)$ \\
\hline Haematology & - & $4(22.2)$ \\
\hline Gynaecology & $4(18.2)$ & $3(16.7)$ \\
\hline Others & $10(45.5)$ & $2(11.1)$ \\
\hline \multicolumn{3}{|c|}{ Medical specialization training achieved } \\
\hline Yes & $20(90.9)$ & $18(100)$ \\
\hline No & $2(9.1)$ & - \\
\hline \multicolumn{3}{|c|}{ Medical practice (years) } \\
\hline Mean (SD) & $17.0(6.5)$ & $13.7(5.5)$ \\
\hline \multicolumn{3}{|c|}{ Medical practice in oncology (years) } \\
\hline Mean (SD) & $13.3(6.8)$ & $11.0(6.4)$ \\
\hline \multicolumn{3}{|c|}{ Number of cancer patients cared for last week } \\
\hline Mean (SD) & $18.7(17.3)$ & $26.2(18.0)$ \\
\hline \multicolumn{3}{|l|}{ Medical practice } \\
\hline In hospital & $18(81.8)$ & $15(83.3)$ \\
\hline In 1-day clinic & $10(45.5)$ & $8(44.4)$ \\
\hline Private & $6(27.3)$ & $5(27.8)$ \\
\hline \multicolumn{3}{|c|}{ Previous workshops in communication skills in the last year } \\
\hline Yes & - & $1(5.6)$ \\
\hline No & $22(100.0)$ & $17(94.4)$ \\
\hline
\end{tabular}

Except when stated otherwise, values are expressed as frequencies; percentages are presented inside parentheses

No statistically significant differences were found between both groups, except for the fact that all haematologists were in the group of physicians with an "external" LOC and the two physicians still in medical specialization training were in the group of physicians with an "internal" LOC 
physicians still in medical specialization training were in the group of physicians with an "internal" LOC (Table 1).

Physicians' attitudes on psychosocial aspects of cancer, burnout symptoms and job stress

Physicians' mean scores on SDAQ scale were 2.79 for attitudes towards oneself ( $\mathrm{SD}=0.57), 3.10$ for attitudes towards cancer and death $(\mathrm{SD}=0.66), 2.34$ for attitudes linked to personal growth $(\mathrm{SD}=0.62), 2.55$ for attitudes linked to professional relationships $(\mathrm{SD}=0.69), 2.86$ for occupational attitudes $(\mathrm{SD}=0.62)$ and 2.74 for the total score $(\mathrm{SD}=0.49)$. As the neutral score on those scales is set to 4 , our subjects have relatively positive attitudes towards the psychosocial aspects of cancer. Although no previous study has focused on medical specialists dealing with cancer patients whose attitudes were assessed using SDAQ, these results fit with the results of previous studies focusing on oncology nurses $[41,52]$. A Student's $t$ test comparison of means showed no significant difference between physicians with an "internal" LOC and physicians with an "external" LOC on these measures (Table 2).

Physicians' mean MBI scores were 18.68 for emotional exhaustion $(\mathrm{SD}=8.12), 6.26$ for depersonalization $(\mathrm{SD}=4.25)$ and 38.94 for personal accompli1shment $(\mathrm{SD}=5.07)$. With regard to those three dimensions, our subjects thus presented a middle level of burnout [43]. The mean score in the personal accomplishment scale in the group of physicians with an "internal" LOC $(M=40.00 ; \mathrm{SD}=5.54)$ was higher than in the group of physicians with an "external" LOC $(M=36.11 ; \mathrm{SD}=4.16)(t=2.463 ; P=0.018)$. Moreover, the mean score in the depersonalization scale in the group of physicians with an "internal" LOC $(M=4.86 ; \mathrm{SD}=3.66)$ was lower than in the group of physicians with an “external" LOC $(M=7.56 ; \mathrm{SD}=4.12)(t=-2.189 ; P=0.035)$ (Table 2). Thus, for those dimensions, physicians with an "internal" LOC presented a lower level of burnout than physicians with an "external" LOC. With regard to burnout level ranges [43], 6 (27.3\%) physicians with an "internal" LOC had a middle level and $4(18.2 \%)$ had a high level of emotional exhaustion; $6(27.3 \%)$ had a middle level and 3 $(13.6 \%)$ had a low level of personal accomplishment; and 3 $(13.6 \%)$ had a middle level and $3(13.6 \%)$ had a high level of depersonalization. Among physicians with an "external" LOC, $8(44.4 \%)$ had a middle level and $3(16.7 \%)$ had a high level of emotional exhaustion; $11(61.1 \%)$ had a middle level and $3(16.7 \%)$ had a low level of personal accomplishment; and $4(22.2 \%)$ had a middle level and $7(38.9 \%)$ had a high level of depersonalization. The numbers in each subgroup did not allow the assessment of the statistical significance of any differences between these groups (chi-square test).

Finally, physicians' mean scores on the JSS were 159.19 for the severity subscale $(\mathrm{SD}=26.61), 139.27$ for the frequency subscale $(\mathrm{SD}=40.09)$ and 74.17 for the job stress index $(\mathrm{SD}=26.26)$. Our subjects' perceived stress severity, frequency and job stress index scores were thus only slightly above the median level. With regard to professional stress, the sample of this study reported a higher level of job stress compared with a sample of working adults employed in university and corporate work settings [45]. These results fit previous studies highlighting that medical specialists face a high amount of stress in their everyday practice [54]. A Student's $t$ test comparison of means showed no statistically significant difference between physicians with an "internal" LOC and physicians with an "external" LOC (Table 2).
Table 2 Comparisons of attitudes on psychosocial aspects of cancer, burnout symptoms and job stress between physicians with an "internal" and physicians with an "external" Locus of Control (LOC) (upper and lower quartiles of the Rotter I-E scale scores distribution) (parametric Strudent's t test)

\begin{tabular}{|c|c|c|c|c|c|c|}
\hline & \multicolumn{2}{|c|}{ Internal LOC } & \multicolumn{2}{|c|}{ External LOC } & \multirow[t]{2}{*}{$\mathrm{t}$} & \multirow[t]{2}{*}{$\mathrm{p}$} \\
\hline & M & SD & M & SD & & \\
\hline \multicolumn{7}{|c|}{ Semantic Differential Attitude Questionnaire (SDAQ) } \\
\hline Attitudes towards oneself & 2.75 & 0.61 & 2.85 & 0.53 & -0.541 & -0.591 \\
\hline Attitudes towards cancer and death & 3.19 & 0.73 & 3.16 & 0.66 & 0.094 & 0.926 \\
\hline Personal growth & 2.21 & 0.77 & 2.49 & 0.48 & -1.315 & 0.197 \\
\hline Professional relationships & 2.55 & 0.64 & 2.78 & 0.85 & -0.994 & 0.327 \\
\hline Occupational attitudes & 2.90 & 0.74 & 2.84 & 0.63 & 0.243 & 0.810 \\
\hline Total score & 2.74 & 0.54 & 2.83 & 0.52 & -0.525 & 0.603 \\
\hline \multicolumn{7}{|l|}{ Maslach Burnout Inventory (MBI) } \\
\hline Emotional exhaustion & 17.82 & 8.24 & 20.00 & 6.14 & -0.931 & 0.358 \\
\hline Personal accomplishment & 40.00 & 5.54 & 36.11 & 4.16 & 2.463 & 0.018 \\
\hline Depersonalisation & 4.86 & 3.66 & 7.56 & 4.12 & -2.189 & 0.035 \\
\hline \multicolumn{7}{|l|}{ Job Stress Survey (JSS) } \\
\hline Severity & 154.68 & 19.84 & 169.50 & 32.13 & -1.789 & 0.082 \\
\hline Frequency & 146.18 & 40.06 & 152.67 & 44.58 & -0.484 & 0.631 \\
\hline Index (severity×frequency) & 76.64 & 22.95 & 85.06 & 30.76 & -0.991 & 0.328 \\
\hline
\end{tabular}


Table 3 Characteristics of interviews led by physicians with an "internal" LOC and physicians with an "external" LOC (upper and lower quartiles of the Rotter I-E scale scores distribution)

\begin{tabular}{|c|c|c|}
\hline Characteristics & $\begin{array}{l}\text { Internal } \\
\text { LOC }\end{array}$ & $\begin{array}{l}\text { External } \\
\text { LOC }\end{array}$ \\
\hline \multicolumn{3}{|l|}{ Patients' age (years) } \\
\hline Mean (SD) & $63(14.2)$ & $66(11.1)$ \\
\hline \multicolumn{3}{|l|}{ Patients' gender ${ }^{\mathrm{a}}$} \\
\hline Male & $6(28.6)$ & $5(29.4)$ \\
\hline Female & $15(71.4)$ & $12(70.6)$ \\
\hline \multicolumn{3}{|l|}{ Patients' school level completed ${ }^{\mathrm{a}}$} \\
\hline Junior high school or less & $11(52.4)$ & $7(41.2)$ \\
\hline High school graduate & $1(4.8)$ & $8(47.1)$ \\
\hline College or university graduate & $9(42.9)$ & $2(11.8)$ \\
\hline \multicolumn{3}{|l|}{ Patients' KPS ${ }^{\mathrm{a}}$} \\
\hline 80 or more & $15(71.4)$ & $15(88.2)$ \\
\hline Less than 80 & $6(28.6)$ & $2(11.8)$ \\
\hline \multicolumn{3}{|l|}{ Patients' HADS } \\
\hline $\begin{array}{l}\text { Emotional distress total mean scores } \\
\text { (SD) }\end{array}$ & $15.7(5.6)$ & $14.1(7.8)$ \\
\hline \multicolumn{3}{|l|}{ Patients’ MHLC } \\
\hline Internal HLC mean scores (SD) & $22.4(6.6)$ & $22.9(4.8)$ \\
\hline External chance HLC mean scores (SD) & $23.3(6.9)$ & $21.9(6.6)$ \\
\hline $\begin{array}{l}\text { External powerful others' HLC mean } \\
\text { scores (SD) }\end{array}$ & $27.1(7.0)$ & $28.9(5.2)$ \\
\hline \multicolumn{3}{|l|}{ Type of cancer $^{\mathrm{a}}$} \\
\hline Solid tumour & $21(100)$ & $14(82.4)$ \\
\hline Haematologic cancer & - & $3(17.6)$ \\
\hline \multicolumn{3}{|l|}{$\operatorname{Prognosis}^{\mathrm{a}}$} \\
\hline Less than 1 year & $7(33.3)$ & $3(17.6)$ \\
\hline 1 year or more & $14(66.7)$ & $14(82.4)$ \\
\hline \multicolumn{3}{|l|}{ Disease status } \\
\hline $\begin{array}{l}\text { In remission, no change or too early to } \\
\text { assess }\end{array}$ & $14(66.7)$ & $12(70.6)$ \\
\hline In progression & $7(33.3)$ & $5(29.4)$ \\
\hline \multicolumn{3}{|l|}{ Current cancer treatment } \\
\hline Yes & $8(38.1)$ & $8(47.1)$ \\
\hline No & $13(61.9)$ & $9(52.9)$ \\
\hline \multicolumn{3}{|l|}{ Months since diagnosis } \\
\hline Mean (SD) & $19(26.1)$ & $35(58.9)$ \\
\hline \multicolumn{3}{|l|}{ Type of information } \\
\hline Diagnosis-related & $14(66.7)$ & $6(35.3)$ \\
\hline Not diagnosis-related & $7(33.3)$ & $11(64.7)$ \\
\hline \multicolumn{3}{|l|}{ Type of news ${ }^{\mathrm{a}}$} \\
\hline Neutral & $5(23.8)$ & $8(47.1)$ \\
\hline Good & $5(23.8)$ & $4(23.5)$ \\
\hline $\mathrm{Bad}$ & $11(52.4)$ & $5(29.4)$ \\
\hline
\end{tabular}

Except when stated otherwise, values are expressed as frequencies; percentages are presented inside parentheses

No statistically significant differences were found between both groups

${ }^{a}$ Chi-square test was not applicable due to a lack of observations in the cells
Patients', relatives' and actual interviews' characteristics

Among the 76 patients met by physicians in the actual interviews, 29 were male and 47 were female. Their mean age was 63 years old ( $\mathrm{SD}=11.7$ years). A total of 36 of them had finished junior high school or less $(47.4 \%), 16$ were high school graduates $(21.1 \%)$ and 24 were college or university graduates $(31.6 \%) ; 62$ of them were able to achieve their daily life activities $(81.6 \%)$ (KPS score $=80$ 100).

The patients' mean HADS total emotional distress score was 13.7 ( $\mathrm{SD}=7.8)$. On average, patients' scores were above the cut-off score of 13, indicative of adjustment disorder. Their mean MHLC scores were $23.1(\mathrm{SD}=5.8)$ for the internal health LOC subscale, $27.7(\mathrm{SD}=6.8)$ for the external chance health LOC subscale and 27.6 $(\mathrm{SD}=5.8)$ for the external powerful others' health LOC subscale.

Table 4 Characteristics of patients' relatives met by physicians with an "internal" LOC and physicians with an "external" LOC (upper and lower quartiles of the Rotter I-E scale scores distribution)

\begin{tabular}{|c|c|c|}
\hline Characteristics & $\begin{array}{l}\text { Internal } \\
\text { LOC }\end{array}$ & $\begin{array}{l}\text { External } \\
\text { LOC }\end{array}$ \\
\hline \multicolumn{3}{|l|}{ Relatives' age (years) } \\
\hline Mean (SD) & $61(14.5)$ & $59(16.7)$ \\
\hline \multicolumn{3}{|l|}{ Relatives' gender } \\
\hline Male & $12(57.1)$ & $7(41.2)$ \\
\hline Female & $9(42.9)$ & $10(58.8)$ \\
\hline \multicolumn{3}{|l|}{ Relatives' school level completed ${ }^{\mathrm{a}}$} \\
\hline Junior high school or less & $10(47.6)$ & $9(52.9)$ \\
\hline High school graduate & $5(23.8)$ & $4(23.5)$ \\
\hline College or university graduate & $6(28.6)$ & $4(23.5)$ \\
\hline \multicolumn{3}{|l|}{ Relatives' KPS } \\
\hline 80 or more & $21(100)$ & $17(100)$ \\
\hline Less than 80 & - & - \\
\hline \multicolumn{3}{|l|}{ Relatives' HADS } \\
\hline $\begin{array}{l}\text { Emotional distress total mean scores } \\
\text { (SD) }\end{array}$ & $15.0(5.3)$ & $15.1(7.9)$ \\
\hline \multicolumn{3}{|l|}{ Relatives' MHLC } \\
\hline Internal HLC mean scores (SD) & $24.4(5.0)$ & $24.4(4.2)$ \\
\hline $\begin{array}{l}\text { External chance HLC mean scores } \\
\text { (SD) }\end{array}$ & $19.1(5.7)$ & $19.9(5.0)$ \\
\hline $\begin{array}{l}\text { External powerful others' HLC mean } \\
\text { scores (SD) }\end{array}$ & $23.3(5.4)$ & $25.8(5.7)$ \\
\hline \multicolumn{3}{|l|}{ Relatives' family ties with patients ${ }^{\mathrm{a}}$} \\
\hline Spouse & $19(90.5)$ & $13(76.5)$ \\
\hline Family member & $1(4.8)$ & $4(23.5)$ \\
\hline Other & $1(4.8)$ & - \\
\hline
\end{tabular}

Except when stated otherwise, values are expressed as frequencies; percentages are presented inside parentheses

No statistically significant differences were found between both groups

${ }^{\mathrm{a}}$ Chi-square test was not applicable due to a lack of observations in the cells 
These scores reflect that our patients have lower scores on the IHLC subscale and higher scores on the PHLC and CHLC subscales than healthy young adults [55]. These results are in accord with other studies which have shown that patients with cancer have lower internal beliefs of control over their health and higher external beliefs than healthy people [56].

Sixty-six patients had a solid tumour diagnosis $(86.8 \%)$ and 54 had a prognosis of 1 year or more (71.1\%). In mean, the diagnosis had been established 23.6 months before the interview ( $\mathrm{SD}=38$ months). For 15 patients, the tumour was in progression (19.7\%) and 36 of them were currently following a cancer treatment regimen (47.4\%). Information given to the patient was diagnosis-related in 40 interviews $(52.6 \%)$. Twenty-seven patients were given neutral news $(35.5 \%), 22$ were given good news $(28.9 \%)$ and 27 were given bad news $(35.5 \%)$.

Among the 76 relatives met by physicians in the actual interview, 62 were the patients' spouses $(81.6 \%), 9$ were family members $(11.8 \%)$ and 5 were other relatives $(6.6 \%)$. Thirty-six were male $(47.4 \%)$ and 40 were female. Their mean age was 58 years old $(\mathrm{SD}=14)$. Thirty-four had finished junior high school or less (44.7\%), 24 were high school graduates $(31.6 \%)$ and 18 were college or university graduates $(23.7 \%)$. All of them were able to achieve their daily life activities (KPS score $=80-100$ ).

The relatives' mean HADS total emotional distress score was $15.2(\mathrm{SD}=7.4)$. On average, relatives' scores were above the cut-off score of 13 , indicative of adjustment disorder. Their mean MHLC scores were $24.3(\mathrm{SD}=4.4)$ for the internal health LOC subscale, $20.2(\mathrm{SD}=5.9)$ for the external chance health LOC subscale and $24.9(\mathrm{SD}=6.3)$ for the external powerful others' health LOC subscale.

Comparisons of interviews' characteristics, led by physicians with an "internal" LOC and physicians with an "external" LOC, showed no statistically significant differences (Tables 3, 4).

\section{Physicians' locus of control and communication skills}

Table 5 shows the results of parametric Student's $t$ test comparisons of mean frequencies of directing utterances and communicative functions used by physicians with an "internal" LOC and physicians with an "external" LOC, as rated with the CRCWEM. As one can see, in the actual interviews, the mean frequency of the utterances directed to the relatives was significantly higher in the group of physicians with an "external" LOC $(M=34.2 ; \mathrm{SD}=22.3)$ compared to the group of physicians with an "internal" LOC $(M=18.7 ; \mathrm{SD}=14.6) \quad(t=2.498 ; P=0.017)$. As the CRCWEM was used to assess the frequencies of physicians' communication skills, the mean frequency of the utterances directed to the patient exclusively was consequently lower in the group of physicians with an "external" LOC $(M=59.0 ; \mathrm{SD}=22.5)$ compared to the group of physicians with an "internal" LOC $(M=73.0 ; \quad \mathrm{SD}=15.6)$ $(t=2.204 ; P=0.034)$. Finally, in the actual interviews, the

Table 5 Comparisons of directing utterances and communicative functions used by physicians with an "internal" LOC and physicians with an "external" LOC in actual and simulated patient interviews

(upper and lower quartiles of the Rotter I-E scale scores distribution; parametric Student's $t$ test)

\begin{tabular}{|c|c|c|c|c|c|c|c|c|c|c|c|c|}
\hline \multirow[t]{3}{*}{ Utterances } & \multicolumn{6}{|c|}{ Actual patient interviews } & \multicolumn{6}{|c|}{ Simulated patient interviews } \\
\hline & \multicolumn{2}{|c|}{ Internal LOC } & \multicolumn{2}{|c|}{ External LOC } & \multirow[t]{2}{*}{$t$} & \multirow[t]{2}{*}{$\mathrm{P}$} & \multicolumn{2}{|c|}{ Internal LOC } & \multicolumn{2}{|c|}{ External LOC } & \multirow[t]{2}{*}{$t$} & \multirow[t]{2}{*}{$\mathrm{p}$} \\
\hline & $M$ & SD & $M$ & SD & & & M & SD & $M$ & SD & & \\
\hline \multicolumn{13}{|l|}{ Directing utterances } \\
\hline To the patient exclusively & 73.0 & 15.6 & 59.0 & 22.5 & 2.204 & 0.034 & 58.2 & 9.7 & 58.3 & 10.8 & -0.033 & 0.974 \\
\hline To the relative (exclusively or not) & 18.7 & 14.6 & 34.2 & 22.3 & -2.498 & 0.017 & 34.7 & 8.5 & 34.9 & 10.0 & -0.083 & 0.934 \\
\hline Unrated & 8.3 & 7.1 & 6.9 & 4.8 & 0.681 & 0.500 & 7.1 & 5.5 & 6.8 & 3.8 & 0.229 & 0.820 \\
\hline \multicolumn{13}{|l|}{ Communicative functions } \\
\hline Introducing-closing & 3.7 & 2.7 & 3.6 & 2.3 & 0.108 & 0.914 & 2.9 & 2.2 & 2.4 & 1.4 & 0.770 & 0.446 \\
\hline Assessing, checking and summarizing & 19.0 & 9.1 & 26.8 & 7.7 & -2.714 & 0.010 & 19.3 & 9.4 & 21.4 & 7.4 & -0.768 & 0.447 \\
\hline Acknowledging & 24.9 & 8.0 & 24.4 & 7.4 & 0.192 & 0.849 & 26.5 & 10.1 & 27.0 & 10.0 & -0.177 & 0.861 \\
\hline Appropriate information & 30.5 & 11.9 & 25.8 & 11.9 & 1.163 & 0.253 & 13.5 & 6.4 & 17.5 & 7.0 & -1.903 & 0.065 \\
\hline Premature information & 9.7 & 8.3 & 8.8 & 5.5 & 0.382 & 0.705 & 26.1 & 12.5 & 18.8 & 7.7 & 2.247 & 0.031 \\
\hline Reassuring and being empathic & 0.5 & 1.2 & 0.1 & 0.3 & 1.118 & 0.271 & 0.5 & 0.7 & 1.3 & 1.3 & -2.276 & 0.029 \\
\hline Premature reassurance & 0.6 & 1.2 & 0.3 & 0.5 & 0.784 & 0.441 & 3.1 & 3.3 & 3.0 & 3.1 & 0.098 & 0.922 \\
\hline $\begin{array}{l}\text { Making educated guesses, confronting to } \\
\text { reality and alerting to reality }\end{array}$ & 0.1 & 0.5 & 0.0 & 0.1 & 0.568 & 0.574 & 0.6 & 1.2 & 0.7 & 1.1 & -0.066 & 0.948 \\
\hline Negotiating & 1.2 & 1.7 & 0.9 & 0.7 & 0.800 & 0.430 & 0.3 & 0.7 & 0.9 & 1.5 & -1.730 & 0.092 \\
\hline Unrated function & 9.8 & 7.1 & 9.2 & 6.4 & 0.255 & 0.800 & 7.3 & 5.3 & 7.0 & 3.8 & 0.158 & 0.875 \\
\hline
\end{tabular}


mean frequency of utterances with an assessment function (assessing, checking and summarizing) was significantly higher in the group of physicians with an "external" LOC $(M=26.8 ; \mathrm{SD}=7.7)$ compared to the group of physicians with an "internal" LOC $(M=19.0 ; \mathrm{SD}=9.1) \quad(t=-2.714$; $P=0.010$ ).

In the simulated interview, the mean frequency of utterances that give premature information was significantly lower in the group of physicians with an "external" LOC $(M=18.8 ; \mathrm{SD}=7.7)$ compared to the group of physicians with an "internal" LOC $(M=26.1 ; \mathrm{SD}=12.5)$ $(t=2.247 ; P=0.031)$. Moreover, in this simulated interview, the mean frequency of utterances with a supportive function such as empathy and reassurance was significantly higher in the group of physicians with an "external" LOC $(M=1.3 ; \mathrm{SD}=1.3)$ compared to the group of physicians with an "internal" LOC $(M=0.5 ; \mathrm{SD}=0.7)(t=-2.276 ; P=0.029)$.

\section{Discussion}

This paper explores the influence of the psychological characteristics of physicians, such as LOC, on their communication styles in interviews with a cancer patient and a relative. We tested the hypothesis that, compared to physicians with an "internal" LOC, who believe that life outcomes are controlled by their own characteristics or actions, physicians with an "external" LOC, who believe that life outcomes are controlled by external forces such as luck, fate or others, would take more into account patients' and relatives' concerns or requests for information, and would consequently talk more to relatives and use more utterances with an assessment function (such as assessing, checking or summarizing), more utterances that give appropriate information and more utterances with a supportive function (such as reassuring, being empathic, making educated guesses, confronting reality or alerting to reality).

Before drawing any conclusions, it must be kept in mind that our sample is more "external" than the American family physicians sample used by May and Revicki [40]. Even if cultural differences could not be excluded, medical practice in oncology may explain this higher level of externality in our sample of physicians. Indeed, facing the uncertainty inherent to cancer and its treatment could increase physicians' beliefs that life outcomes are in part controlled by external factors like chance, fate or luck. Moreover, it could not be excluded that more "internal" physicians would be more reluctant or would feel less need to take part in communication skills training as they may feel in control of their relationships with their cancer patients. Finally, Student's $t$ test comparisons between both groups of physicians showed that physicians with "external" LOC reported less personal accomplishments and a higher level of depersonalization on the MBI subscales than physicians with "internal" LOC. Physicians with "external" LOC, moreover, tended to report perceived stress severity more than physicians with "internal" LOC. This confirms results of numerous previous researches which have established that subjects with "external" LOC are less efficient in coping with stress (e.g. Krause and Stryker [57]).

In actual interviews, as hypothesized, physicians with an "external" LOC, compared to physicians with an "internal" LOC, talked more to relatives and used more utterances with an assessment function. Meanwhile, physicians with an "external" LOC neither used more utterances that give appropriate information nor used more utterances with a supportive function. The absence of differences between both groups of physicians regarding the use of these skills may be explained by the fact that speaking to the relative and using utterances with an assessment function could have reduced the time that physicians with an "external" LOC had available to give more appropriate information and support.

In simulated interviews, contrary to our hypothesis, physicians with an "external" LOC did not talk more to the relatives and did not use more utterances with an assessment function than physicians with an "internal" LOC. This could be due to the fact that, in this study, the simulated relative was instructed to play an active role in the interview. This role implied a spontaneous expression of concerns and requests for information that could have reduced the physicians' choice to include or not the simulated relative in the interview and to use more or fewer utterances with an assessment function. Both groups of physicians, however, still had the choice to take into account or not these spontaneous expressions of concerns and requests for information in order to provide information and support. In this context, physicians with an "external" LOC used less utterances that give premature information, tended to use more utterances that give appropriate information and used more utterances with a supportive function, such as empathy and reassurance, than physicians with an "internal" LOC. It should be recalled that information is rated, in this study, as appropriate only if it is given after exploring the patients' or the relatives' feelings and if the information given is realistic and takes into account the interview's coherence. Physicians with an "external" LOC, compared to physicians with an "internal" LOC, thus took the results of their assessment more into account when they informed and supported their patients and relatives.

The abovementioned results are similar to results of a previous study showing that physicians with an "external" LOC used more utterances that give appropriate information in interviews with cancer patients who were not accompanied by a relative [15]. In this previous study, 81 voluntary physicians practising in the field of oncology were recorded while performing an actual and a simulated interview with a cancer patient who was not accompanied 
by a relative. As in this previous study, physicians with an "external" LOC included in the current study are more able to appropriately give information to the patient and the relative than physicians with an "internal" LOC (less utterances that give premature information). In contrast, physicians with an "external" LOC who are included in the current study talked more to the relative and used more utterances with an assessment function in actual interviews than physicians with an "internal" LOC. Moreover, in the current study, in simulated interviews, physicians with an "external" LOC used more utterances with a supportive function, such as empathy and reassurance, than physicians with an "internal" LOC. The results of these two studies confirm that physicians' LOC is a psychological characteristic that influences their communication styles in interviews with a cancer patient alone, as well as in interviews with a cancer patient and a relative. Compared to physicians with an "internal" LOC, physicians with an "external" LOC take more into account the expression of concerns or requests for information of the persons they are talking to. Moreover, physicians with an "external" LOC also use more communication skills that promote this disclosure of concerns or requests for information when their interlocutors do not express them or request for information spontaneously than physicians with an "internal" LOC.

These results could be explained by the concept of LOC itself. Physicians with an "external" LOC believe that life outcomes are more controlled by external forces such as luck, fate or others than by their own characteristics or actions. They could therefore be more focused on external cues such as the patients' and their relatives' concerns or requests for information and could thus respond by giving appropriate information and using more supportive skills. Results also show that they use more communication skills promoting patients' disclosure of concerns. In contrast, physicians with an "internal" LOC believe that life outcomes are more controlled by their own characteristics or actions than by external forces such as others. Compared to physicians with an "internal" LOC, they could therefore be more focused on their own representation of what their interlocutors' concerns or need for information may be in order to give information and support. They may thus be less prone to using communication skills that promote the expression of concerns of their interlocutors.

The results of this study should not lead to the conclusion that physicians with an "external" LOC are more patient-centred than physicians with an "internal" LOC. A true patient-centred communication implies a higher level of communication skills mastery and that physicians' communication style should be more determined by the patients' characteristics than by the physicians' characteristics. These results thus only highlight that physicians'
LOC influences their communication styles and may thus interfere with a patient-centred communication.

Theoretical models have previously suggested that the psychological characteristics of physicians, such as knowledge and attitudes, outcome expectancies, self-efficacy or perceived professional support, can influence physicians' communication skills in their interviews with cancer patients [11]. The results of this study, as well as those of our previously published study [15], constitute the first empirical evidence that physicians may have different communication styles and that these styles may be influenced by a psychological characteristic. This highlights the fact that physicians' communication skills are influenced not only by the patients' characteristics but also by their own psychological characteristics. The results of this study constitute an empirical evidence of this.

This study indicates a need to test a model of physicians' communication skills, including physicians' LOC, among other factors that could influence their abilities to be patient-centred. In this model, further studies should test the impact of patients' socio-demographic, psychological and social characteristics, as well as of the interviews' characteristics on these abilities. Among their psychological characteristics, patients' LOC and its association with their behaviours in interviews such as question asking could be tested.

These results may increase physicians' awareness that their own psychological characteristics may interfere with the way they communicate. This awareness may help them differentiate the actual concerns or requests for information of each particular patient and relative from their own representations of what patients' and relatives' concerns or need for information could be. As this awareness may lead physicians to tailor their communication skills to every patient's and relative's concerns and needs, it may promote a more patient-centred communication. It should be recalled that tailoring communication skills to every individual patient's and relative's concerns and needs is one of the main objectives of communication skills training programs $[58,59]$.

Acknowledgements We thank the physicians, patients and their relatives who participated in the study. For their contribution to the training program, we thank Darius Razavi, Nicole Delvaux and Serge Marchal. For their contribution to the data collection, we thank Laurence Dubus, Jean-François Durieux and Angélique Moucheux. For contributions to the data analyses, we thank JeanLouis Slachmuylder. For their contribution to the quality control of the transcripts and the rating of the interviews, we thank Nicolas Beauloye, Véronique Beddegenoots, Youri Caels, Anne Chevalier, Caroline Dhozot, Michel De Cock, Christine Farvacques, Emilie Harcq, Sandrine Kranich, Christophe Luthy, Maggie Oda, Fiona Roe and Fiona Vandenbossche. We also thank Viviane De Beer, Maria Del Pilar Pato Fernandez, Fabienne Hubert, Immaculée Mukarwego, Françoise Odou, Claudia Ortega and Monique Toussaint for the transcription of the interviews. 


\section{References}

1. Mead N, Bower P (2000) Patientcentredness: a conceptual framework and review of the empirical literature. Soc Sci Med 51:1087-1110

2. Epstein RM, Hundert EM (2002) Defining and assessing professional competence. JAMA 287:226-235

3. Maguire P (1990) Can communication skills be taught? Br J Hosp Med 43:215-216

4. Fallowfield L, Jenkins V (1999) Effective communication skills are the key to good cancer care. Eur J Cancer 35:1592-1597

5. Novack DH (1987) Therapeutic aspects of the clinical interview. J Gen Intern Med 2:346-355

6. Bakker DA, Fitch MI, Gray R, Reed E, Bennett J (2001) Patient-health care provider communication during chemotherapy treatment: the perspectives of women with breast cancer. Patient Educ Couns 43:61-71

7. Maguire P (1999) Improving communication with cancer patients. Eur J Cancer 35:1415-1422

8. Montgomery C, Lydon A, Lloyd K (1999) Psychological distress among cancer patients and informed consent. J Psychosom Res 46:241-245

9. Croyle RT, Lerman C (1999) Risk communication in genetic testing for cancer susceptibility. J Natl Cancer Inst Monogr 25:59-66

10. Blaney PH (1986) Affect and memory: a review. Psychol Bull 99:229-246

11. Parle M, Maguire P, Heaven C (1997) The development of a training model to improve health professionals' skills, self-efficacy and outcome expectancies when communicating with cancer patients. Soc Sci Med 44:231-240

12. Rotter JB (1966) Generalized expectancies for internal versus external control of reinforcement. Psychol Monogr 80:1-28

13. Doherty WJ (1983) Impact of divorce on locus of control orientation in adult women: a longitudinal study. J Pers Soc Psychol 44:834-840

14. De Brabander B, Declerck CH (2004) A possible role of central dopamine metabolism associated with individual differences in locus of control. Pers Individ Differ 37:735-750

15. Libert Y, Janne P, Razavi D, Merckaert I, Scalliet P, Delvaux N, Etienne AM, Conradt S, Klastersky J, Boniver J, Reynaert C (2003) Impact of medical specialists' locus of control on communication skills in oncological interviews. Br J Cancer 88:502-509
16. Beisecker AE, Moore WP (1994) Oncologists' perceptions of the effects of cancer patients' companions on physician-patient interactions. J Psychosoc Oncol 12:23-39

17. Labrecque MS, Blanchard CG, Ruckdeschel JC, Blanchard EB (1991) The impact of family presence on the physician-cancer patient interaction. Soc Sci Med 33:1253-1261

18. Kurtz ME, Kurtz JC, Given CC, Given B (1996) Concordance of cancer patient and caregiver symptom reports. Cancer Pract 4:185-190

19. Lobchuk MM, Kristjanson L, Degner L, Blood P, Sloan JA (1997) Perceptions of symptom distress in lung cancer patients: congruence between patients and family caregivers. J Pain Symptom Manage 14:136-146

20. Kristjanson LJ, Nikoletti S, Porock D, Smith M, Lobchuk M, Pedler P (1998) Congruence between patients' and family caregivers' perceptions of symptom distress in patients with terminal cancer. J Palliat Care 14:24-32

21. Lobchuk MM, Degner LF (2002) Symptom experiences: perceptual accuracy between advanced stage cancer patients and family caregivers in the home care setting. J Clin Oncol 20:3495-3507

22. Pitceathly C, Maguire P (2003) The psychological impact of cancer on patients' partners and other key relatives: a review. Eur J Cancer 39:15171524

23. Toseland RW, Blanchard CG, McCallion P (1995) A problem solving intervention for caregivers of cancer patients. Soc Sci Med 40:517-528

24. Carnwath TC, Johnson DA (1987) Psychiatric morbidity among spouses of patients with stroke. BMJ 294:409411

25. Evans RL, Bishop DS, Matlock AL, Stranahan S, Smith GG, Halar EM (1987) Family interaction and treatment adherence after stroke. Arch Phys Med Rehabil 68:513-517

26. Cassileth BR, Lusk EJ, Strouse TB, Miller DS, Brown LL, Cross PA (1985) A psychological analysis of cancer patients and their next-of-kin. Cancer 55:72-76

27. Newsom JT, Schulz R (1998) Caregiving from the recipient's perspective: negative reactions to being helped. Health Psychol 17:172-181

28. Greene MG, Majerovitz SD, Adelman RD, Rizzo C (1994) The effects of the presence of a third person on the physician-older patient medical interview. J Am Geriatr Soc 42:413-419
29. Delvaux N, Merckaert I, Marchal S, Libert Y, Conradt S, Boniver J, Etienne AM, Fontaine O, Janne P, Klastersky J, Melot C, Reynaert C, Scalliet P, Slachmuylder JL, Razavi D (2005) Physicians' communication with a cancer patient and a relative. Cancer 103:2397-2411

30. Gordon J, Sanson-Fisher R, Saunders NA (1988) Identification of simulated patients by interns in a casualty setting. Med Educ 22:533-538

31. Ainsworth MA, Rogers LP, Markus JF, Dorsey NK, Blackwell TA, Petrusa ER (1991) Standardized patient encounters: a method for teaching and evaluation. JAMA 266:1390-1396

32. Barrows HS (1993) An overview of the uses of standardised patients for teaching and evaluating clinical skills. Acad Med 68:443-451

33. Maguire P, Booth K, Elliott C, Jones B (1996) Helping health professionals involved in cancer care acquire key interviewing skills - the impact of workshops. Eur J Cancer 32A:14861489

34. Maguire P, Faulkner A, Booth K, Elliott C, Hillier V (1996) Helping cancer patients disclose their concerns. Eur J Cancer 32A:78-81

35. Razavi D, Delvaux N, Marchal S, De Cock M, Farvacques C, Slachmuylder JL (2000) Testing health care professionals' communication skills: the usefulness of highly emotional standardized role-playing sessions with simulators. Psychooncology 9:293-302

36. McKinlay JB, Lin T, Freund K, Moskowitz M (2002) The unexpected influence of physician attributes on clinical decisions: results of an experiment. J Health Soc Behav 43:92-106

37. Yedidia MJ, Gillespie CC, Kachur E, Schwartz MD, Ockene J, Chepaitis AE, Snyder CW, Lazare A, Lipkin M Jr (2003) Effect of communications training on medical students performance. JAMA 290:1157-1165

38. Booth C, Maguire P (1991) Development of a rating system to assess interaction between cancer patients and health professionals. Report to Cancer Research Campaign, London

39. Salehi I (1981) La théorie de l'apprentissage social de la personnalité de J. B. Rotter: le concept de lieu de contrôle du renforcement. J Thér Comport Cogn 2:103-117

40. May HJ, Revicki DA (1985) Professional stress among family physicians. J Fam Pract 20:165-171 
41. Razavi D, Delvaux N, Marchal S, Bredart A, Farvacques C, Paesmans M (1993) The effects of a 24 hours psychological training programme on attitudes, communication skills and occupational stress in oncology: a randomised study. Eur J Cancer 29A:1858-1863

42. Silberfarb PM, Levine PM (1980) Psycho-social aspects of neoplastic disease. III Group support for the oncology nurse. Gen Hosp Psychiatry 3:192-197

43. Dion G, Réjean T (1994) Validation de la traduction de l'Inventaire d'Epuisement Professionnel de Maslach et Jackson. Rev Can Sci Comport 26:210-227

44. Maslach C, Jackson S (1986) Maslach burnout inventory: manual, 2nd edn. Consulting Psychologists Press, Palo Alto, CA

45. Vagg PR, Spielberger CD (1999) The Job Stress Survey: assessing perceived severity and frequency of occurrence of generic sources of stress in the workplace. J Occup Health Psychol 4:288292

46. Spielberger CD, Reheiser EC (1994) The Job Stress Survey: measuring gender differences in occupational stress. J Soc Behav Pers 9:199-218
47. Zigmond AS, Snaith RP (1983) The hospital anxiety and depression scale. Acta Psychiatr Scand 67:361-370

48. Razavi D, Delvaux N, Farvacques C, Robaye E (1990) Screening for adjustment disorders and major depressive disorders in cancer in-patients. $\mathrm{Br}$ J Psychiatry 156:79-83

49. Wallston KA, Wallston BS (1982) Who is responsible for your health? The construct of health locus of control. In: Sanders G, Suls J (eds) Social psychology and health and illness. Erlbaum, Hillsdale, NJ, pp 65-95

50. Wallston KA, Stein MJ, Smith CA (1994) Form C of the MHLC scales: a condition-specific measure of locus of control. J Pers Assess 63:534-553

51. Karnofsky DA, Burcheval JH (1949) The clinical evaluation of chemotherapeutic agents in cancer patient. In: McLeod CM (eds) Evaluation of chemotherapeutic agents. Colombia University Press, New York

52. Grieco A, Lung C (1984) Investigation of the Karnofsky Performance Status as a measure of quality of life. Health Psychol 3:129-142

53. Delvaux N, Razavi D, Marchal S, Bredart A, Farvacques C, Slachmuylder JL (2004) Effects of a 105 hours psychological training program on attitudes, communication skills and occupational stress in oncology: a randomised study. Br J Cancer 90:106-114
54. Ramirez AJ, Graham J, Richards MA, Timothy AR (1996) Stress at work for the clinical oncologist. Clin Oncol 8:137-139

55. Steptoe A, Wardle J (2001) Locus of control and health behaviour revisited: a multivariate analysis of young adults from 18 countries. Br J Psychol 92:659-672

56. Wallston KA (1992) Hocus-pocus, the focus isn't strictly on locus: Rotter's social learning theory modified for health. Cogn Ther Res 16:183-199

57. Krause N, Stryker S (1984) Stress and well-being: the buffering role of locus of control beliefs. Soc Sci Med 18:783790

58. Fallowfield L, Jenkins V, Farewell V, Saul J, Duffy A, Eves R (2002) Efficacy of a Cancer Research UK communication skills training model for oncologists: a randomised controlled trial. Lancet 359:650-656

59. Razavi D, Merckaert I, Marchal S, Libert Y, Conradt S, Boniver J et al (2003) How to optimise physicians' communication skills in cancer care: results of a randomised study assessing the usefulness of post training consolidation workshops. J Clin Oncol 21:3141-3149 